\title{
Role of FMRP in rapid antidepressant effects and synapse regulation
}

\author{
Chelcie F. Heaney $\mathbb{D}^{1,2} \cdot$ Sanjeev V. Namjoshi ${ }^{1} \cdot$ Ayse Uneri $^{1} \cdot$ Eva C. Bach ${ }^{1,2} \cdot$ Jeffrey L. Weiner ${ }^{1,2}$. \\ Kimberly F. Raab-Graham (iD) ${ }^{1,2}$
}

Received: 22 March 2019 / Revised: 23 November 2020 / Accepted: 1 December 2020 / Published online: 12 January 2021

(c) The Author(s) 2021. This article is published with open access

\begin{abstract}
Rapid antidepressants are novel treatments for major depressive disorder (MDD) and work by blocking N-methyl-Daspartate receptors (NMDARs), which, in turn, activate the protein synthesis pathway regulated by mechanistic/mammalian target of rapamycin complex 1 (mTORC1). Our recent work demonstrates that the RNA-binding protein Fragile X Mental Retardation Protein (FMRP) is downregulated in dendrites upon treatment with a rapid antidepressant. Here, we show that the behavioral effects of the rapid antidepressant Ro-25-6981 require FMRP expression, and treatment promotes differential mRNA binding to FMRP in an mTORC1-dependent manner. Further, these mRNAs are identified to regulate transsynaptic signaling. Using a novel technique, we show that synapse formation underlying the behavioral effects of Ro-25-6981 requires $\mathrm{GABA}_{\mathrm{B}} \mathrm{R}$-mediated $\mathrm{mTORC} 1$ activity in WT animals. Finally, we demonstrate that in an animal model that lacks FMRP expression and has clinical relevance for Fragile X Syndrome (FXS), GABA $\mathrm{B}_{\mathrm{B}} \mathrm{R}$ activity is detrimental to the effects of Ro-25-6981. These effects are rescued with the combined therapy of blocking $\mathrm{GABA}_{\mathrm{B}}$ Rs and NMDARs, indicating that rapid antidepressants alone may not be an effective treatment for people with comorbid FXS and MDD.
\end{abstract}

\section{Introduction}

Over the past 50 years, treatment for major depressive disorder (MDD) has been limited [1], with selective serotonin reuptake inhibitors (SSRIs) as the most commonly prescribed treatment for the general population. Recently, MDD treatment entered a new era with the discovery that glutamate $\mathrm{N}$-methyl-D-aspartate receptor (NMDAR) antagonists produce antidepressant-like effects [2], perhaps through blocking NMDARs containing the 2B subunit (GluN2B) [3]. Importantly, these drugs have a rapid onset and work in a treatment-resistant population, with relief of MDD symptoms within hours of a single infusion that can

Supplementary information The online version of this article (https:// doi.org/10.1038/s41380-020-00977-z) contains supplementary material, which is available to authorized users.

Kimberly F. Raab-Graham

kraabgra@wakehealth.edu

1 Department of Physiology and Pharmacology, Wake Forest University Health Sciences, 1 Medical Center Boulevard, Winston-Salem, NC 27157, USA

2 Wake Forest Translational Alcohol Research Center (WF-TARC), Wake Forest University Health Sciences, 1 Medical Center Boulevard, Winston-Salem, NC 27157, USA last up to a week [4-6]. Thus, NMDAR antagonists are considered paradigm-shifting treatments for MDD [7].

Activation of mechanistic/mammalian target of rapamycin complex 1 (mTORC1), a serine-threonine kinase that regulates protein synthesis and promotes new synapse formation, is key to reducing MDD symptoms through NMDAR antagonism [8]. mTORC1 regulates protein synthesis in dendrites by utilizing mRNAs that are targeted and translated in a site-specific and temporal fashion. The coordinated expression of these mRNAs, which code for proteins involved in synaptic and structural plasticity $[9,10]$, may be regulated by RNA-binding proteins (RBPs). Our recent work suggests that NMDAR antagonism rapidly downregulates dendritic expression of the RBP Fragile X Mental Retardation Protein (FMRP) [11]. While FMRP is extensively characterized in the context of autism spectrum disorder (ASD), its role in MDD and MDD treatments is unclear.

FMRP is one of the best characterized RBPs, affecting mRNA trafficking [12], mRNA repression in dendrites [13], and is implicated in Fragile X Syndrome (FXS), the leading single-gene cause of ASD [14, 15]. Loss-of-function mutations in the FMR1 gene, which codes for FMRP [16], lead to FXS. Notably, people who are FMR1 premutation carriers exhibit higher rates of MDD and depressed mood compared to the general population [17-19]. People with ASD have an 
increased risk of developing MDD by the time they are 30 years old compared to people without ASD [20], and caretakers of people with FXS identify mood and depression as a priority for treatment development [21]. Moreover, SSRIs do not produce an antidepressant-like effect in an animal model of FXS [22], suggesting that people with comorbid FXS and MDD may be treatment resistant to traditional MDD pharmacotherapies.

Critical questions arise in light of these data: (1) is FMRP required for the rapid antidepressant properties of NMDAR antagonists? (2) given the importance of mTORC1 signaling in rapid antidepressant efficacy, do mTORC1 and FMRP regulate specific cellular functions? and (3) are rapid antidepressants an effective treatment for MDD in FXS?

Herein, we demonstrate that rapid antidepressantmediated transsynaptic signaling and presynaptic engagement are mTORC1-dependent and are required for new synapse formation. These mechanisms underlying the rapid antidepressant efficacy of the GluN2B-specific antagonist Ro-25-6981 require activity-dependent FMRP expression. Moreover, we demonstrate that, unlike wildtype (WT) mice, treatment with Ro-25-6981 alone is insufficient to promote new synapse formation or antidepressant-like effects on behavior in Fmrl knockout (KO) mice, similar to SSRIs [22]. Finally, we provide data that $\gamma$-aminobutyric acid $B$ receptor $\left(G_{A B} A_{B} R\right)$ signaling prevents the actions of Ro-25-6981 in Fmrl KO mice. Blocking $\mathrm{GABA}_{\mathrm{B}} \mathrm{Rs}$ with the specific antagonist CGP35348 restores the antidepressant-like effect on behavior and increases synapse number when coadministered with Ro-25-6981 in Fmrl KO mice. Importantly, our findings propose a new combination therapy effective to treat MDD in FXS.

\section{Materials and methods}

Detailed materials and methods are outlined in Supplementary Materials and Methods

\section{Animals}

Male and female WT (C57BL/6, Jackson Laboratory) and Fmr1 KO (B.6129P2-Fmr1tm1Cgr/J, Jackson Laboratory) mice between the ages of 2 and 5 months were used. All animals were randomly assigned to treatment groups. We found no significant effect of sex or sex $\times$ treatment interaction (data presented in Supplementary Materials and Methods). All experiments were carried out in accordance with the National Institutes of Health's Guide for the Care and Use of Laboratory Animals and approved by the Wake Forest Institutional Animal Care and Use Committee.

\section{Pharmacology}

For behavioral and in vivo experiments, animals received intraperitoneal (i.p.) injections of Ro-25-6981 $(10 \mathrm{mg} / \mathrm{kg}$, Tocris, 1594) with or without CGP35348 (100 mg/kg; Tocris, 1245$)$, or $0.9 \%$ physiological saline vehicle $(0.01$ $\mathrm{ml} / \mathrm{g}$, LabChem). Animals in the RNA immunoprecipitation (RIP)-Seq experiment received either Ro-25-6981 (10 mg/ $\mathrm{kg})$ with or without rapamycin $(6 \mathrm{mg} / \mathrm{kg}$; LC Laboratories, \#R-5000) or $0.9 \%$ physiological saline $(200 \mu \mathrm{l})$. For in vitro experiments, Ro-25-6981 (10 $\mu \mathrm{M})$, rapamycin $(200 \mathrm{nM})$, and baclofen $(50 \mu \mathrm{M}$; Tocris, \#0796) were used. Vehicle controls cells were treated with water (vehicle for Ro-256981 and baclofen) and/or 0.1\% DMSO (vehicle for rapamycin).

\section{Forced swim test (FST)}

Animals were placed into a glass cylinder filled with water $23-25^{\circ} \mathrm{C}$ for $6 \mathrm{~min}$; animals were quickly removed at the end, dried, and returned to their warmed homecage. Each animal was run in two FST sessions (see Fig. 1a for timeline); the first session acutely stressed the animals, and the second session, $24 \mathrm{~h}$ after the first, was video recorded and scored for immobility in the last 4 min using Ethovision (version 11.5, Noldus).

\section{Splash test}

Animals were individually assessed in their homecage by applying $200 \mu \mathrm{l}$ of $10 \%$ sucrose to their dorsal coat. Animals were video recorded for $5 \mathrm{~min}$ and later scored for grooming behavior (licking, grooming with forepaws, and scratching).

\section{RNA immunoprecipitation}

Animals were sacrificed 45 min after drug administration, and cortices were rapidly dissected out and flash frozen on dry ice (Fig. S1A). RIP-Seq was modified from previous methods shown to significantly reduce background mRNA binding [23, 24].

\section{Immunoblotting}

Animals were sacrificed $45 \mathrm{~min}$ after drug administration, and cortices were processed according to previously published methods [11, 25-27].

\section{Immunohistochemistry and in vivo proximity ligation assay (PLA)}

Animals were deeply anesthetized $45 \mathrm{~min}$ after drug administration and underwent transcardial perfusion. Brains 


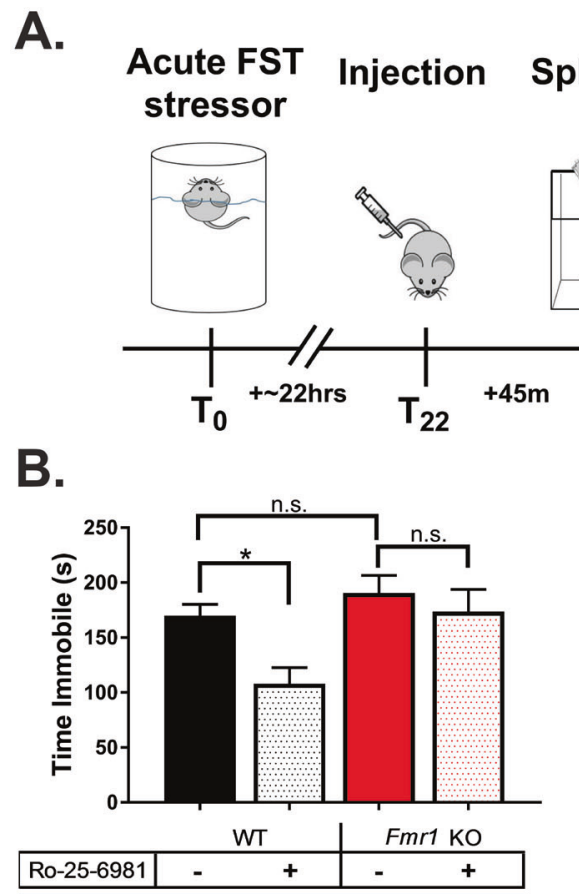

Fig. 1 The rapid antidepressant behavioral effects of Ro-25-6981 require FMRP expression. a Representative timeline of behavioral procedures. Twenty-four hours prior to the recorded forced swim test (FST), animals were acutely stressed with FST. Approximately $22 \mathrm{~h}$ later, animals received a single i.p. injection of their randomly assigned treatment. Forty-five minutes after the injection, animals underwent the splash test, and $30 \mathrm{~min}$ after that, they were exposed to a second FST. b WT animals treated with Ro-25-6981 significantly decreased immobility in the FST, but Fmrl KO mice did not respond to treatment. Two-way ANOVA revealed a significant main effect of treatment $\left(F_{1,58}=6.152, p=0.0161\right)$ and genotype $\left(F_{1,58}=7.386\right.$, $p=0.0087)$ but did not find a significant genotype $\times$ treatment interaction. Newman-Keuls post hoc test revealed a significant difference between WT control $(169.9 \pm 10.4 \mathrm{~s}, n=14)$ vs. WT Ro-25-6981

were sectioned $25 \mu \mathrm{m}$ thick on a Leica SM2010F sliding microtome and put into cryoprotectant. Slices were permeabilized and blocked before overnight primary antibody incubation at $4{ }^{\circ} \mathrm{C}$. Slices underwent a 2-h incubation at $37^{\circ}$ C (PLA) or RT (immunohistochemistry) in secondary antibodies, then incubated in ligase for $30 \mathrm{~min}$ at $37^{\circ} \mathrm{C}$ (PLA). Finally, slices underwent the amplification/polymerase step for $2 \mathrm{~h}$ at $37^{\circ} \mathrm{C}$ (PLA).

\section{Cell culture and in vitro PLA}

Primary neuronal hippocampal cultures were prepared from postnatal day 0-3 mouse pups from WT or Fmrl KO mice according to previously published methods [11, 25-27]. Cells were plated between 70 and 100,000 per $12 \mathrm{~mm}$ on glass coverslips, and cultures were used at 18-21 days in vitro. Drug treatments were done in media. Fixed neurons were blocked and permeabilized and then incubated with primary antibodies for $1 \mathrm{~h}$ at RT, followed by secondary antibody
FST

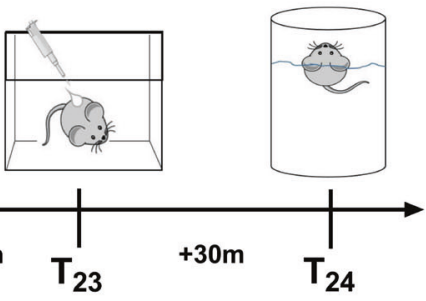

C.

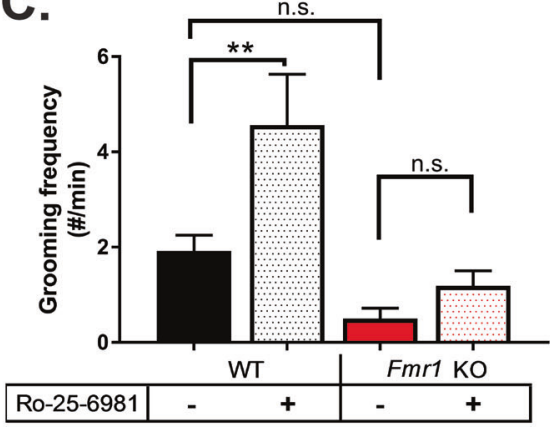

$(108.1 \pm 14.7 \mathrm{~s}, n=17)$, but no significant difference between KO control $(190.5 \pm 16.0 \mathrm{~s}, n=16)$ and KO Ro-25-6981 $(173.7 \pm 20.0 \mathrm{~s}$, $n=15)$. KO control and KO Ro-25-6981 were significantly more immobile than WT Ro-25-6981. c Similarly, Ro-25-6981-treated WT animals increased grooming frequency but treated $\mathrm{Fmrl} \mathrm{KO}$ mice did not. Two-way ANOVA revealed a significant main effect of treatment $\left(F_{1,57}=7.29, p=0.0091\right)$ and genotype $\left(F_{1,57}=15.16, p=0.0003\right)$, but there was not a significant genotype $\times$ treatment interaction. Newman-Keuls post hoc test revealed a significant difference between WT control (1.92 \pm 0.32 times per minute, $n=13)$ vs. WT Ro-25-6981 (4.56 $\pm 1.06, n=16)$, but no significant difference between KO control $(0.5 \pm 0.22$ times per minute, $n=16)$ and KO Ro-25-6981 (1.18 \pm $0.31, n=16)$. Bars represent mean \pm SEM. $* p<0.05$, $* * p<0.01$, n.s. not significant.

incubation for $1 \mathrm{~h}$ at RT (immunocytochemistry) or $37^{\circ} \mathrm{C}$ (PLA). PLA coverslips were then incubated with ligation solution for $30 \mathrm{~min}$ at $37^{\circ} \mathrm{C}$, followed by incubation in amplification/polymerase buffer for $100 \mathrm{~min}$ at $37^{\circ} \mathrm{C}$.

\section{Microscopy and analysis}

All images within a given experiment were acquired and analyzed using the same settings with a Nikon A1plus confocal microscope. Images were analyzed with Nikon NIS-Elements AR (version 4.40.00).

\section{Statistical analyses}

Prism (version 7.05, GraphPad) was used for all statistical analyses. Statistical comparisons were made using Student's $t$ test, one-way analysis of variance (ANOVA), or two-way ANOVA where appropriate. Newman-Keuls post hoc tests were performed in the event of significant ANOVAs. Outliers 
were determined using Grubbs' test $(\alpha=0.05)$. All data are expressed as mean \pm standard error of the mean (SEM).

\section{Results}

\section{The rapid antidepressant behavioral effects of Ro- 25-6981 require FMRP expression}

We recently showed that dendritic FMRP expression is rapidly reduced in WT dendrites after treatment with the GluN2B-specific antagonist Ro-25-6981, suggesting that activity-dependent expression of FMRP and FMRPdependent translation in dendrites may be necessary for antidepressant efficacy [11]. To test this hypothesis, we treated acutely stressed WT and Fmrl KO mice with a single i.p. injection of Ro-25-6981 (see Fig. 1a for timeline). We then analyzed performance in two wellcharacterized behavioral tasks that measure antidepressant efficacy - the FST, a measure of behavioral despair, and the splash test, a measure of motivated self-care [2, 28-31]. Because the splash test uses sucrose, one could argue that this task measures reward-related behavior. However, WT and Fmrl KO mice do not display baseline differences in sucrose preference [32]; further, others show that the splash test is sensitive enough to detect behavioral changes due to stress and antidepressant treatment without showing changes to sucrose preference [33]. Consistent with our previous results [25, 26], Ro-25-6981-treated WT animals are mobile about $60 \mathrm{~s}$ more in the FST (Fig. 1b) and groom about twice as frequently in the splash test (Fig. 1c), indicative of an antidepressant-like effect. However, Ro-25-6981 does not affect performance in either task when administered to Fmrl KO mice. Together, these results confirm our hypothesis that the RBP FMRP is required for the behavioral effects of rapid antidepressants.

\section{mTORC1-sensitive FMRP-target mRNAs are regulated by Ro-25-6981 treatment}

Next, we set out to identify the FMRP-target mRNAs regulated by Ro-25-6981, which may underlie its antidepressant efficacy. We treated WT and Fmrl KO mice with Ro-25-6981 and collected brains 45 min post administration, a time point where behavioral changes [25] and mTORC1 activation [2] are observed. Cortices were processed for RIP, followed by RNASeq (RIP-Seq), using a specific antibody against FMRP [34] (see Supplementary Materials and Methods, Figs. S1-S3, and Tables S1-S3 for RIP-Seq data preprocessing, filtering, and quality control). As a control for nonspecific binding, FMRP-RIP was performed, in parallel, on Fmrl KO cortices. Ro-25-6981 treatment promoted the differential binding of 283 transcripts to FMRP relative to control (Fig. 2a; light blue circle). These data indicate that FMRP regulates the availability of mRNAs for translation in response to Ro-25-6981 treatment.

We and others show that rapid antidepressants, including Ro-25-6981, increase mTORC1-dependent synthesis of several synaptic proteins necessary for its antidepressant effects $[2,25,26]$. To identify the mTORC1-sensitive transcripts among the 283 FMRP-target mRNAs we identified, we performed RIP-Seq on cortices from mice coinjected with Ro-25-6981 plus the mTORC1 inhibitor rapamycin. We then compared the differentially regulated FMRP-target mRNAs sensitive to both Ro-25-681 treatment (Fig. 2a, light blue circle) and mTORC1 activity (Fig. 2a, light red circle). Differential gene expression analysis between these two treatments revealed 190 overlapping transcripts (false discovery rate cutoff of 0.1 ; Fig. 2a, b; Tables S4 and S5) [35]. Of these overlapping FMRP-target mRNAs sensitive to both Ro-25-6981 treatment and mTORC1 activity, $99.5 \%$ change in the same direction $(58.9 \%$ upregulated/released, $40.5 \%$ downregulated/bound) (Fig. S1B). FMRP is best known for repressing mRNA translation [36], and we expected that treatment with Ro-25-6981 would induce FMRP to release select transcripts to be translated ( $\sim 59 \%$ are released/upregulated). We were surprised to find that FMRP also bound a new set of target mRNAs ( 41\% become bound/downregulated). To verify our RIP-Seq results, we identified target mTORC1-sensitive mRNAs that were either bound to (Fmrl) or released from (Prkaca) FMRP after Ro-25-6981 treatment (Fig. 2c, Table S5). We analyzed FMRP and PKA $\mathrm{C}-\alpha$ protein expression in vivo $45 \mathrm{~min}$ after treatment. As expected, we found that mice treated with Ro-25-6981 express significantly less FMRP, in line with our previous results [11], and more PKA C- $\alpha$ in cortical lysates by Western blot analysis (Fig. 2d). Together, these data verify our RIP-Seq results and suggest that Ro-25-6981 regulates the dynamic expression of FMRP and PKA C- $\alpha$.

\section{FMRP-target mRNAs regulate transsynaptic signaling}

Next, we used the Database for Annotation, Visualization and Integrated Discovery (DAVID 6.8) [37, 38] to cluster the resulting transcripts based on their coordinated biological processes (gene ontology, GO), to identify critical mechanisms mediated by Ro-25-6981/mTORC1/FMRP (Fig. 3a, b). These analyses revealed transsynaptic signaling to be the most significantly enriched GO cluster in both conditions (Fig. 3a, control/Ro; Fig. 3b, Ro + Rapa/Ro). We used biomaRt [39-41] to identify the genes associated with transsynaptic signaling, which were then intersected with our data set to determine the fold changes for these 
A.

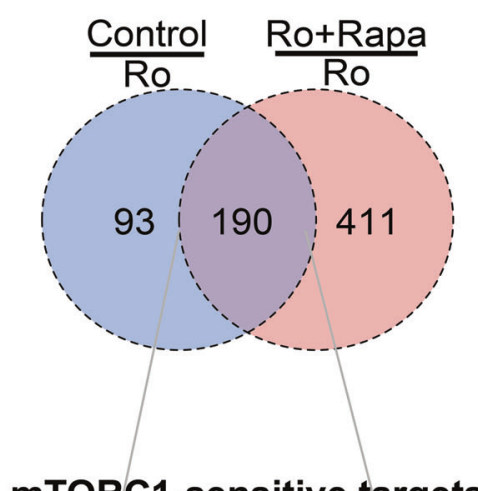

mTORC1-sensitive targets

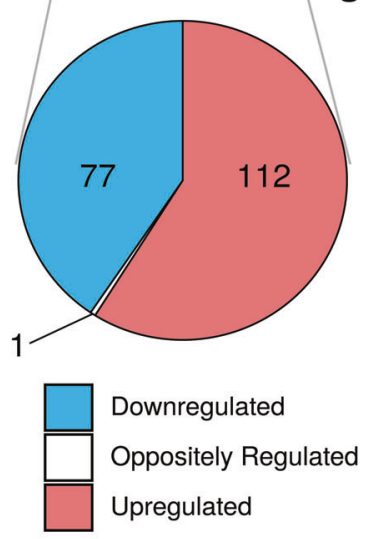

C.

\begin{tabular}{ccc}
$F m r 1$ & logFC & adj.P.Val \\
\hline Control/Ro & -0.3093 & 0.0772 \\
Ro+Rapa/Ro & -0.5727 & 0.0059
\end{tabular}

D.
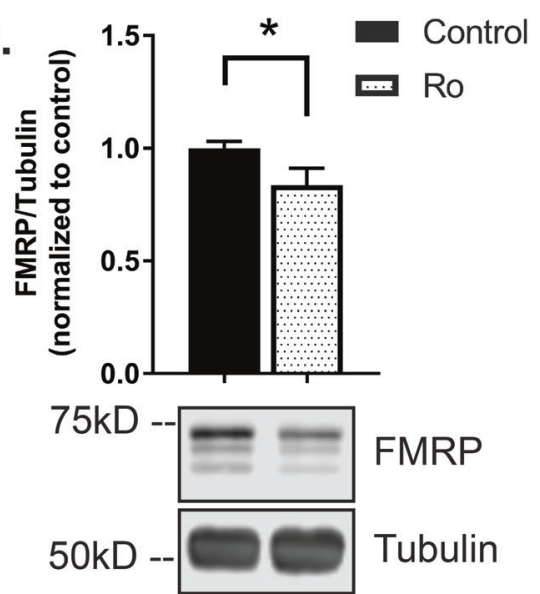

genes based on condition. Notably, of the 190 Ro-25-6981/ mTORC1-sensitive FMRP-target mRNAs (Fig. 2a), 60\% are transsynaptic (Fig. 3c, upper right quadrant, Fig. S4D, Table S5). These analyses suggest that regulating transsynaptic signaling is a specific role for the FMRP-target mRNAs sensitive to both mTORC1 activity and Ro-256981 treatment.
B.

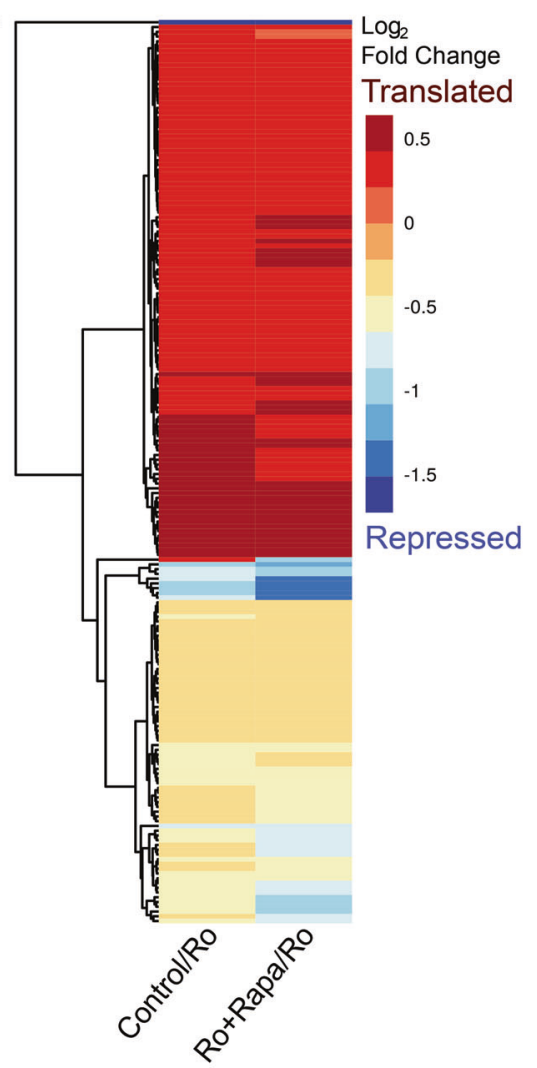

\begin{tabular}{ccc} 
Prkaca & logFC & adj.P.Val \\
\hline Control/Ro & 0.4812 & 0.0231 \\
Ro+Rapa/Ro & 0.4086 & 0.0161
\end{tabular}
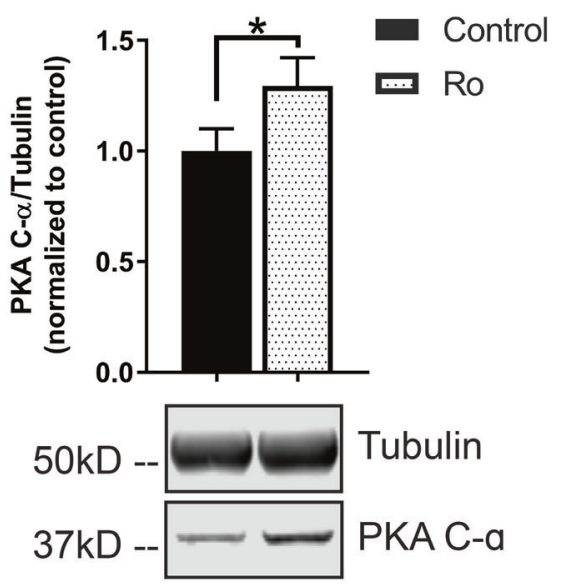

\section{Transsynaptic signaling requires both NMDAR blockade and $\mathrm{GABA}_{\mathrm{B}} \mathrm{R}$-mediated mTORC1 activation}

Transsynaptic signaling facilitates the coordinated communication of pre- and postsynaptic terminals [42]. In addition, new synapse formation is suggested to underlie rapid antidepressant efficacy [2]. We have previously shown that 
Fig. 2 mTORC1-sensitive FMRP-target mRNAs are regulated by Ro-25-6981 treatment. a Top: Venn diagram of differentially expressed mRNAs isolated in control/Ro-25-6981 or Ro-25-6981 + rapamycin/Ro-25-6981 conditions with the FDR cutoff of 0.1 (same mRNAs as in b). Bottom: Breakdown of $\log _{2}$ fold change direction of mRNAs in the intersection of the Venn diagram, indicative of the mRNAs that are sensitive to both treatment of Ro-25-6981 and mTORC1 activity. See Tables S4 and S5 for a complete list of genes and fold changes. The single mRNA that is oppositely regulated is Dbp, a transcription factor implicated in regulating circadian rhythm. b Clustered dendrogram and heatmap for $\log _{2}$ fold change for the treatments. Targets are the same as those in the pie chart in a. Dendrogram created using the average linkage method and Euclidean distance metric. Positive fold changes indicate mRNAs are released from FMRP and presumably translated with Ro-25-6981 treatment; negative fold changes indicate that more mRNAs are bound to FMRP with Ro-25-6981 treatment compared to the control (indicative of mRNA repression with Ro-25-6981 treatment) or Ro + Rapa (indicative that mTORC1 activity is needed for mRNAs to be released with Ro-25-6981 treatment) conditions. c In both control/Ro-25-6981 and Ro-25-6981 + rapamycin/Ro-25-6981 conditions, Fmrl has a negative fold change, indicating Fmrl mRNAs remain bound to FMRP with Ro-25-6981 treatment and is mTORC1 sensitive. Conversely, Prkaca has a positive fold change in both control/Ro-25-6981 and Ro25-6981 + rapamycin/Ro-256981 conditions, indicating that Prkaca mRNAs are released from FMRP with Ro-25-6981 treatment and is mTORC1 sensitive. Significance determined with the FDR cutoff of 0.1 . d Verification that protein expression of FMRP decreases [11] (control $=1.0 \pm 0.03$ normalized optical density, $n=8$; Ro-25-6981 = $\left.0.83 \pm 0.07, n=8 ; t_{14}=2.008, p=0.0322\right)$ and PKA C- $\alpha$ increases (control $=1.0 \pm 0.10$ normalized optical density, $n=7$; Ro-25-6981 = $\left.1.29 \pm 0.12, n=7 ; t_{12}=1.797, p=0.0488\right)$ with Ro-25-6981 treatment in cortical lysates $45 \mathrm{~min}$ after treatment. $* p<0.05$.

activation of traditionally inhibitory $\mathrm{GABA}_{\mathrm{B}} \mathrm{Rs}$ in the presence of an NMDAR antagonist unexpectedly increases L-type calcium channel activity, which thereby increases dendritic mTORC1 activation and downstream protein synthesis [25, 26]. To validate that Ro-25-6981 affects transsynaptic signaling, we capitalized on the ability to tightly control mTORC1 activity in the cell culture system. We measured the expression of two prototypical synaptic proteins that specifically localize to post- and presynaptic terminals: postsynaptic density 95 (PSD-95) and synapsin-1 (SYN1), respectively [2, 34]. Notably, both NMDAR antagonism and $\mathrm{GABA}_{\mathrm{B}} \mathrm{R}$ activity are required to activate mTORC1 [25]. Thus, we treated cultured primary hippocampal neurons (see Fig. 4a for timeline) with Ro-25-6981 (no mTORC1 activity in vitro), Ro-25-6981 with the GABA $_{B}$ agonist baclofen (mTORC1 activity in vitro), or Ro-25-6981 with baclofen and the mTORC1 inhibitor rapamycin (mTORC1 blocked in vitro). We found that GluN2B-specific antagonism increased the expression of the postsynaptic marker PSD-95 in an mTORC1independent manner (Fig. 4b, c). In contrast, the expression of the presynaptic marker SYN1 increased only in the neurons with mTORC1 activity (Ro-25-6981 + baclofen; Figs. 4b, d and S5A). When we measured colocalization of PSD-95 with SYN1, however, we did not find a significant
A.

Control/Ro

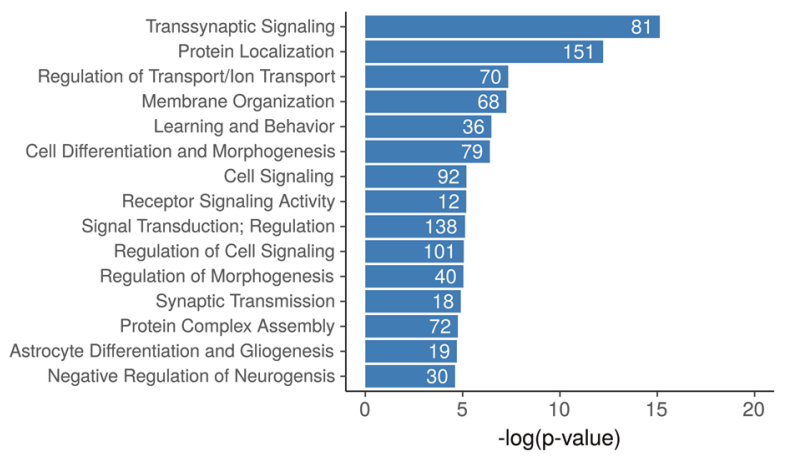

B.

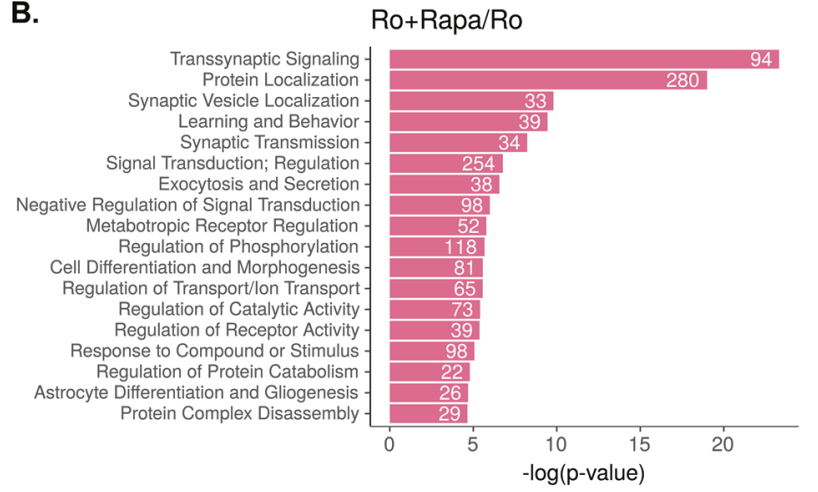

C.

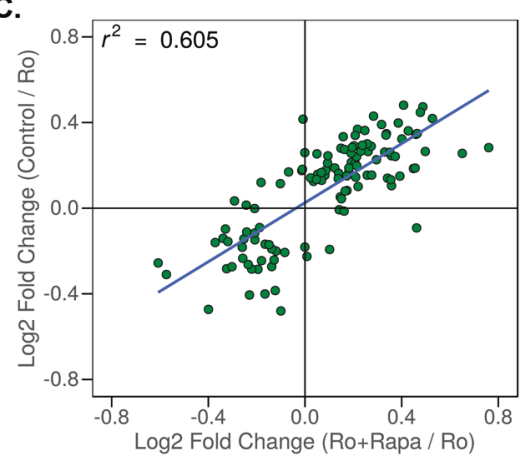

Fig. 3 FMRP-target mRNAs regulate transsynaptic signaling. a Uniquely enriched GO biological process clusters for FMRP targets identified by RIP-Seq where $\log _{2}$ (control/Ro-25-6981 fold change) $>0$ (blue) and b $\log _{2}$ (Ro-25-6981 + Rapa/Ro-25-6981 fold change) $>0$ (pink). Transsynaptic signaling is the most significantly enriched GO cluster in both conditions. c Scatterplot showing $\log _{2}$ (control/Ro-256981 fold change) $>0 \quad \log _{2}$ (Ro-25-6981 + Rapa/Ro-25-6981 fold change) $>0$ of the mTORC1-sensitive transsynaptic targets (upper right quadrant). Supplementary Tables S4 and S5 contain the complete list of identified targets.

effect of treatment (Fig. 4e), likely due to these proteins being juxtaposed vs. overlapping. Realizing the limitations of colocalization as a correlate of synapse number, we developed a fluorescent assay that could detect pre- and postsynaptic engagement and, thus, indicate new synapse formation. Array tomography studies demonstrate that postsynaptic PSD-95 and presynaptic SYN1 localize within $40 \mathrm{~nm}$ of each other [43]. We surmised we could utilize a PLA to detect protein-protein interactions between 
A.

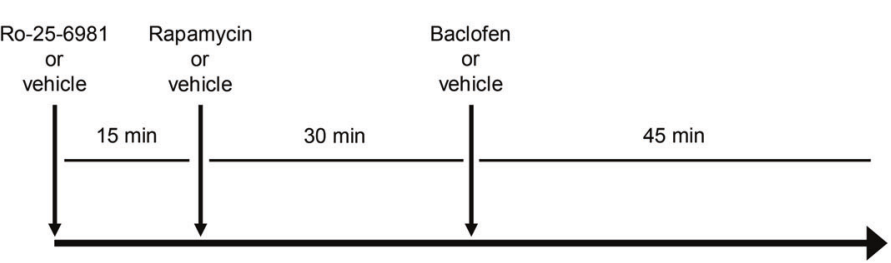

B.

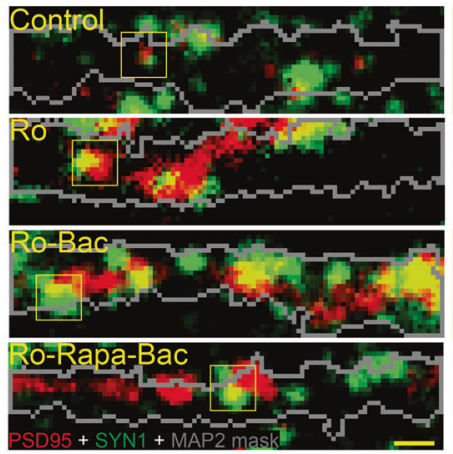

F.
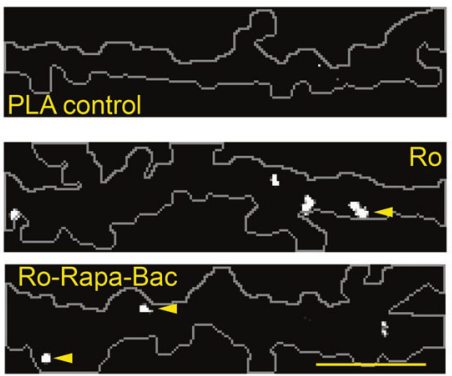

C.

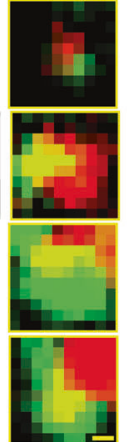

D.

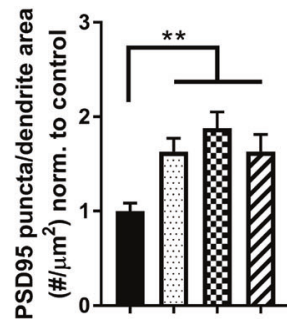

\begin{tabular}{c|cccc}
\hline Ro-25-6981 & - & + & + & + \\
\hline Baclofen & - & - & + & + \\
\hline Rapamycin & - & - & - & +
\end{tabular}
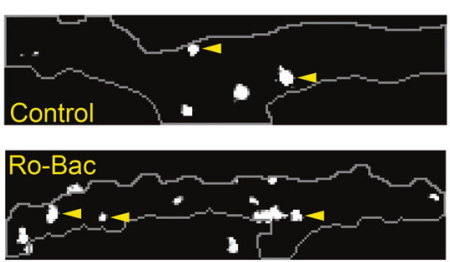

MAP2 mask + PSD95/SYN1 PLA puncta

H.

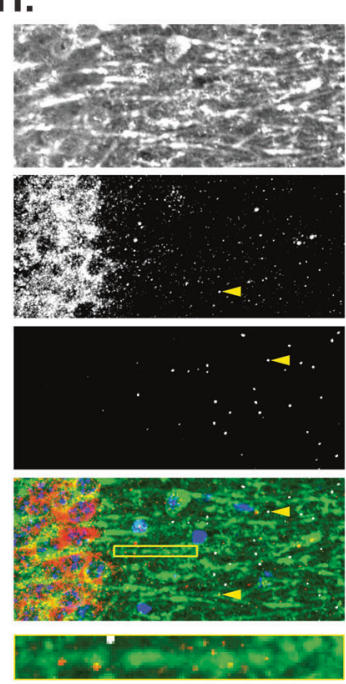

Control
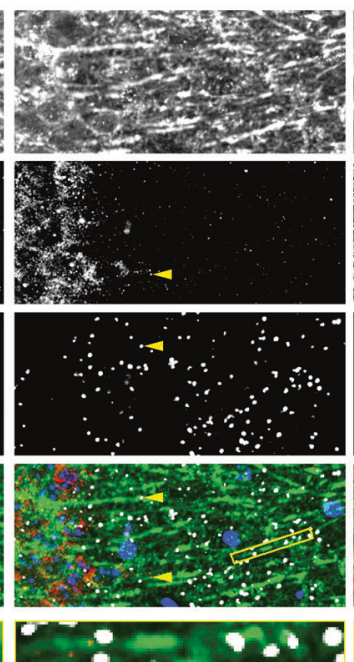

Ro-25-6981
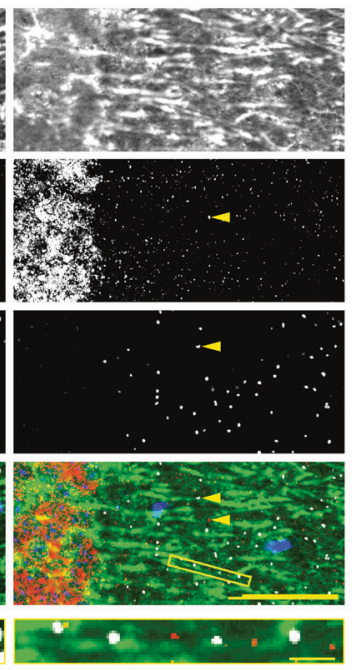

Ro-25-6981+CGP35348

MAP2

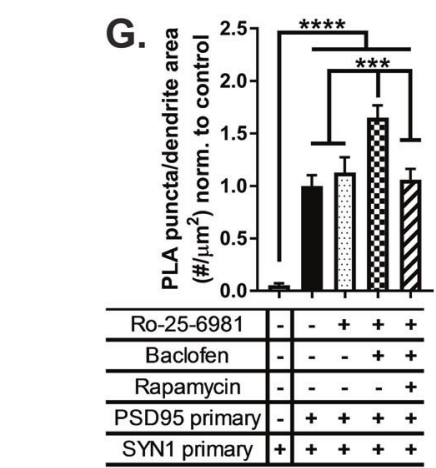

\begin{tabular}{|c|c|c|c|c|}
\hline Ro-25-6981 & & \pm & +4 & \\
\hline Baclofen & & - & -1 & \\
\hline Rapamycin & & & 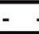 & \\
\hline SD95 primary & & & \pm & \\
\hline YN1 primary & & & & \pm \\
\hline
\end{tabular}

E.

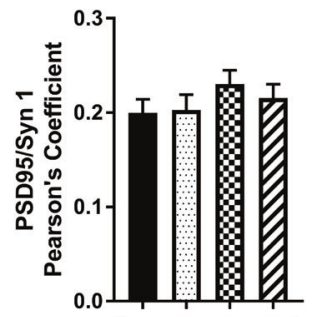

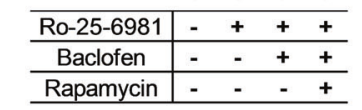

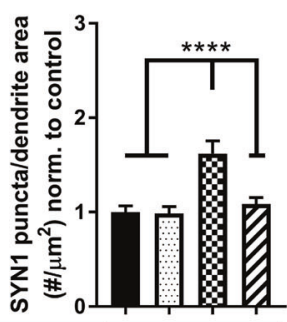

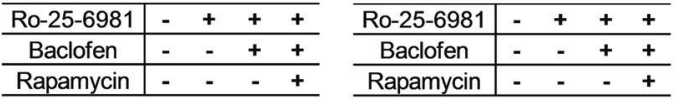

proximal pre- and postsynaptic proteins located across the synaptic cleft within 0-40 nm. Consistent with our immunostaining data, NMDAR antagonism alone (Ro-25-6981) did not increase synapse formation, as indicated by no change in PLA puncta number relative to control (Fig. 4f, g). However, when we activated mTORC1 (Ro-25-6981+ 
Fig. 4 Transsynaptic signaling requires both NMDAR blockade and GABA $_{B} R$-mediated mTORC1 activation. a Timeline of treatments for neuronal culture experiments in $\mathbf{b}$ and $\mathbf{f}$. b Representative immunofluorescence images of treated WT hippocampal neurons stained for PSD-95 (red), SYN1 (green), and MAP2 (gray outline). Panels depict $10 \mu \mathrm{m}$ segments of dendrites, at least $20 \mu \mathrm{m}$ from the soma; scale $b a r=1 \mu \mathrm{m}$. Highlighted boxes indicate representative SYN1 and PSD-95 staining; scale bar $=0.2 \mu \mathrm{m}$. c Quantification of average number of PSD-95 puncta within dendritic MAP2 area by treatment. PSD-95 expression increased in all treatments in an mTORC1-independent manner. One-way ANOVA revealed a significant main effect of treatment $\left(F_{3,184}=6.303, p=0.0004\right)$. Newman-Keuls post hoc test revealed a significant difference between control $(1.0 \pm 0.08$ normalized optical density, $n=49)$ vs. Ro-25-6981 $(1.63 \pm 0.14, n=46)$, control vs. Ro-25-6981 + baclofen $(1.88 \pm 0.17$, $n=41)$, and control vs. Ro-25-6981 + rapamycin + baclofen $(1.63 \pm$ $0.17, n=52$ ). d Quantification of average number of SYN1 puncta within dendritic MAP2 area by treatment. One-way ANOVA revealed a significant main effect of treatment $\left(F_{3,184}=11.14, p<0.0001\right)$. Newman-Keuls post hoc test revealed Ro-25-6981 + baclofen $(1.61 \pm$ 0.13 normalized optical density, $n=41$ ) significantly increased the number of SYN1 puncta compared to control-treated neurons $(1.0 \pm$ $0.06, n=49)$, as well as neurons treated with Ro-25-6981 (0.98 \pm 0.07 , $n=46)$ and Ro-25-6981 + rapamycin + baclofen $(1.08 \pm 0.06, n=$ 52), indicating an mTORC1-dependent effect. e Quantification of Pearson's correlation coefficient of PSD-95 and SYN1 by treatment. One-way ANOVA did not reveal a significant effect of treatment for the correlation between PSD-95 and SYN1 $\left(F_{3,186}=0.8282, p=\right.$ 0.4799). f Representative dendritic traces of treated hippocampal neurons. White puncta represent proximity-detected PSD-95 and SYN1 proteins by PLA (indicated by yellow arrowheads), and gray outline represents MAP2 staining of the neuron. Puncta at least 12.5 $\mu \mathrm{m}$ from the soma were analyzed. Scale bar $=10 \mu \mathrm{m}$. $\mathrm{g}$ Quantification of the average number of PSD-95/SYN1 PLA puncta per dendritic MAP2 area. One-way ANOVA revealed a significant main effect of treatment $\left(F_{4,581}=18.25, p<0.0001\right)$. Newman-Keuls post hoc test revealed Ro-25-6981 + baclofen $\left(1.65 \pm 0.11 \mathrm{puncta} / \mu \mathrm{m}^{2}\right.$ normalized to control, $n=132$ ) significantly increased the number of PSD-95/ SYN1 PLA puncta compared to control-treated $\left(1.0 \pm 0.10 \mathrm{puncta} / \mu^{2}\right.$ normalized, $n=119)$, Ro-25-6981-treated $\left(1.12 \pm 0.14 \mathrm{puncta} / \mu \mathrm{m}^{2}\right.$ normalized, $n=125)$, and Ro-2506981+rapamycin + baclofen-treated $\left(1.06 \pm 0.10 \mathrm{puncta} / \mu \mathrm{m}^{2}\right.$ normalized, $\left.n=143\right)$ neurons. In addition, PLA control neurons $\left(0.05 \pm 0.01\right.$ puncta/ $\mu \mathrm{m}^{2}$ normalized, $\left.n=67\right)$ showed a significant lack of puncta compared to all other treatments. $\mathbf{h}$ Representative images of treated WT CA1 stratum radiatum dendrites. White puncta represent proximity-detected PSD-95 and SYN1 proteins by PLA, and red puncta represent FMRP (yellow arrowheads indicate representative puncta of each). i Quantification of the average number of PSD-95/SYN1 PLA puncta per area of CA1 stratum radiatum dendrites. Puncta at least $10 \mu \mathrm{m}$ from the pyramidal layer were analyzed. One-way ANOVA revealed a significant main effect of treatment $\left(F_{2,52}=6.79, \quad p=0.0024\right)$. Newman-Keuls post hoc test revealed that treatment with Ro-25-6981 $\left(4.68 \pm 0.78\right.$ puncta $/ \mu^{2}$ normalized to control, $n=23)$ significantly increased PSD-95/SYN1 PLA puncta $45 \mathrm{~min}$ after treatment compared to control $(1.0 \pm 0.11$ puncta/ $\mu \mathrm{m}^{2}$ normalized, $\left.n=13\right)$ and Ro-25-6981 + CGP35348 (2.58 $\pm 0.64 \mathrm{puncta} / \mu \mathrm{m}^{2}$ normalized, $\left.n=19\right)$. This increase is blocked with the $\mathrm{GABA}_{\mathrm{B}} \mathrm{R}$ antagonist CGP35348 (no significant difference between control and Ro-25-6981 + CGP35348). $\mathbf{j}$ Protein expression of FMRP decreases with Ro-25-6981 treatment in CA1 stratum radiatum dendrites $45 \mathrm{~min}$ after treatment (control $=1.0 \pm 0.12$ normalized optical density, $n=19$; Ro-25-6981 $=0.70 \pm 0.07, n=23 ; t_{40}=2.026, p=$ 0.0247). Scale bar $=50 \mu \mathrm{m}$. Representative dendrites shown below to demonstrate the puncta are located on dendrites. Scale bar $=5 \mu \mathrm{m}$. Bars represent mean \pm SEM. $* p<0.05, * * p<0.01, * * * p<0.001$, $* * * * p<0.0001$, n.s. not significant. baclofen), the number of detectable PLA puncta in dendrites increased by $\sim 65 \%$ (Fig. 4f, g). Further, when we inhibited mTORC1 with rapamycin (Ro-25-6981 + Rapa + Bac), the number of detected synapses decreased back to baseline (Fig. 4f, g). Thus, GABA ${ }_{B} R$-mediated mTORC1 activation is required for presynaptic engagement for synapse formation with Ro-25-6981.

We next verified that the change in synapse number detected in vitro is reflected in vivo. Because there are few inhibitory neurons in hippocampal cultures [44, 45], baclofen is necessary to activate $\mathrm{GABA}_{\mathrm{B}} \mathrm{Rs}$ in vitro. However, in vivo treatment of ketamine or Ro-25-6981 is sufficient to increase endogenous GABA [46] and promote mTORC1 activity and antidepressant-like effects on behavior $[25,26]$. Therefore, we inhibited $\mathrm{GABA}_{B} \mathrm{Rs}$ to investigate the effects of $\mathrm{GABA}_{\mathrm{B}} \mathrm{R}$-mediated mTORC1 activity in vivo. Thus, we treated WT mice with Ro-25-6981 or Ro25-6981 and the specific $\mathrm{GABA}_{\mathrm{B}} \mathrm{R}$ antagonist CGP35348 to block $\mathrm{GABA}_{B} \mathrm{R}$ signaling and downstream mTORC1 activation [25]. Indeed, consistent with our in vitro PLA results, we found that Ro-25-6981 treatment increased the number of detected synapses and that inhibiting mTORC1 activity with CGP35348 prevented this increase (Figs. 4h, i and S5B, C). Further, dendritic FMRP expression decreased in these same slices with Ro-25-6981 treatment, which returned to baseline expression when $\mathrm{GABA}_{\mathrm{B}} \mathrm{R}$ signaling was blocked with Ro-25-6981+ CGP35358 (Fig. 4h, j).

\section{$\mathrm{GABA}_{B} \mathrm{R}$ activity is detrimental to synapse formation and rapid antidepressant efficacy of Ro-25-6981 in a preclinical mouse model of FXS}

Next, we sought to validate the requirement of FMRP expression for mTORC1-dependent synapse formation upon treatment with Ro-25-6981. We replicated the PLAsynapse assay in hippocampal slices from Fmrl KO mice. We predicted that if the activity-dependent release of FMRP-target mRNAs is required for mTORC1-dependent transsynaptic signaling and synapse formation, then the relative increase in synapses detected by PLA upon treatment will be absent in the Fmrl KO mouse. Surprisingly, we instead found a significant decrease of about $43 \%$ in the number of detected synapses in Fmrl KO mice treated with Ro-25-6981 (Fig. 5a, b). Further, treatment with Ro-256981 and CGP35348 unexpectedly reversed this decrease and significantly increased the number of detected synapses by about $47 \%$ compared to control animals (Fig. 5a, b). These data suggest that in the presence of FMRP expression, $\mathrm{GABA}_{\mathrm{B}} \mathrm{R}$ signaling is required for rapid antidepressant-mediated synaptogenesis; however, when FMRP expression is absent, $\mathrm{GABA}_{\mathrm{B}} \mathrm{R}$ signaling is detrimental and needs to be blocked for synaptogenesis to occur. 
A.

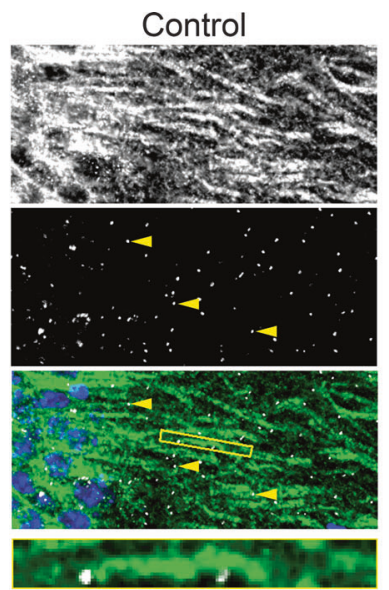

Ro-25-6981

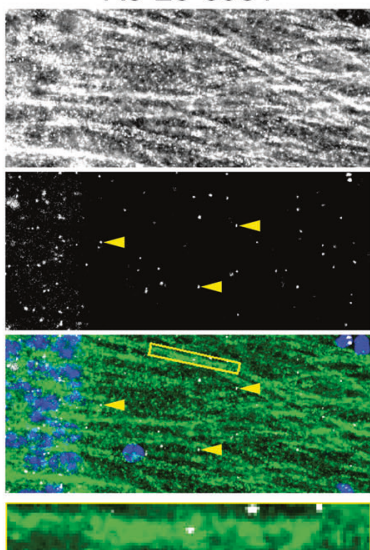

Ro-25-6981+CGP35348

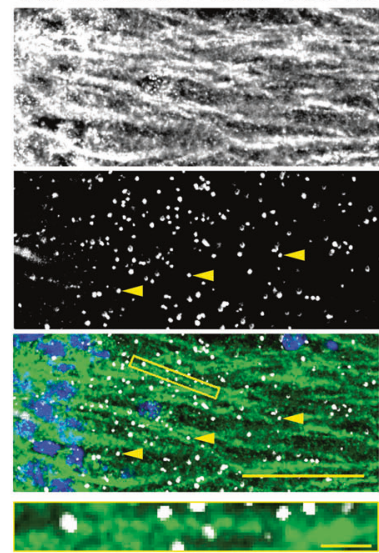

MAP2

PSD95/SYN1

PLA puncta

Merged
B.

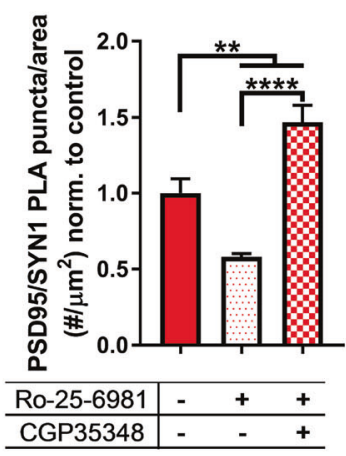

C.

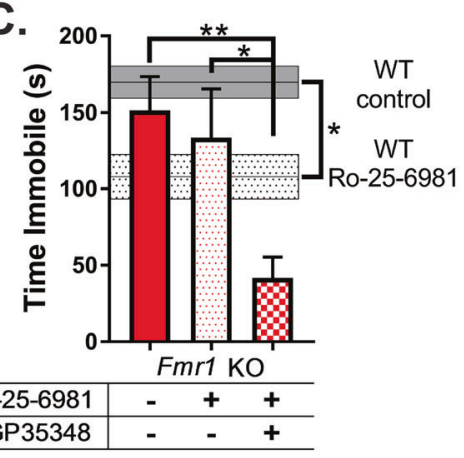

D.

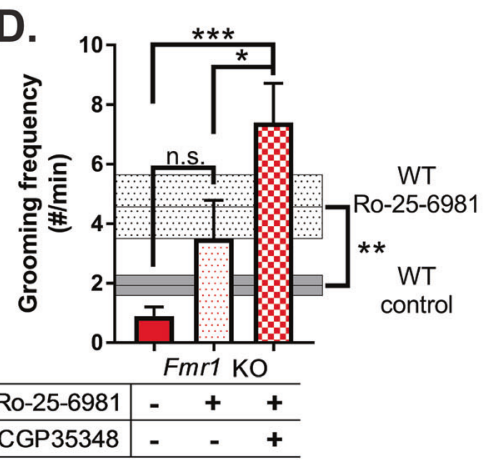

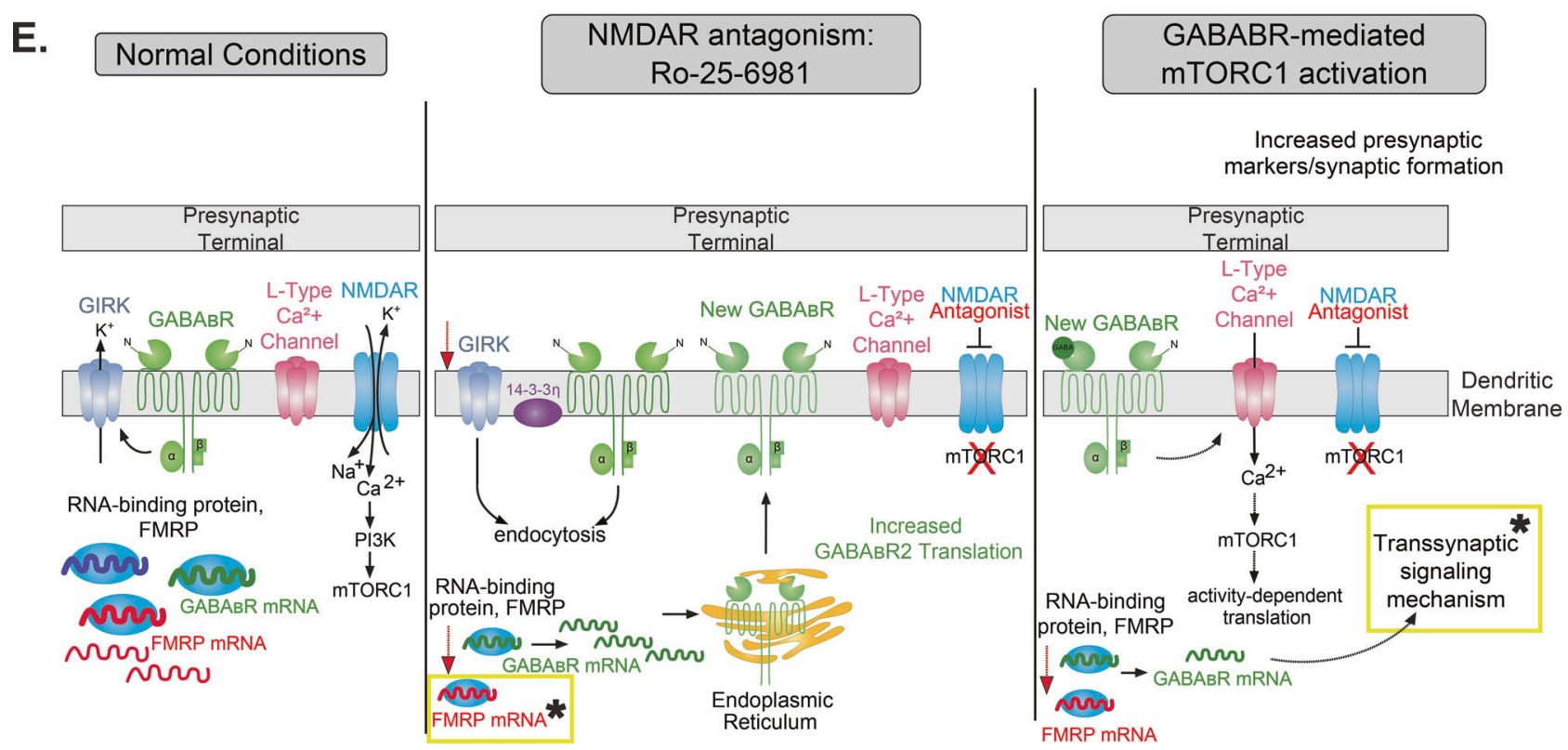

If the increase in synapses in WT animals underlies the efficacy of Ro-25-6981 as a rapid antidepressant, we thus questioned whether blocking $\mathrm{GABA}_{\mathrm{B}} \mathrm{R}$ activity in conjunction with Ro-25-6981 treatment would promote an antidepressant-like effect on behavior in Fmrl KO animals. We tested this hypothesis by examining the effect of Ro-25-
6981 with or without the $\mathrm{GABA}_{\mathrm{B}} \mathrm{R}$ antagonist CGP35348 on behavior of Fmrl KO mice in the FST and splash test (see Fig. 1a for timeline). Indeed, Fmrl KO animals treated with Ro-25-6981 + CGP35348 decreased immobility in the FST by about $100 \mathrm{~s}$ (Fig. 5c) and increased grooming frequency in the splash test by nearly eight times compared to 
Fig. 5 GABA $_{\mathrm{B}} \mathrm{R}$ activity is detrimental to synapse formation and rapid antidepressant efficacy of Ro-25-6981 in a preclinical mouse model of FXS. a Representative images of treated KO CA1 stratum radiatum dendrites. White puncta represent proximity-detected PSD95 and SYN1 proteins by PLA (indicated by yellow arrowheads). Scale bar $=50 \mu \mathrm{m}$. Representative dendrites shown below to demonstrate the puncta are located on dendrites. Scale bar $=5 \mu \mathrm{m}$. b Quantification of the average number of PSD-95/SYN1 PLA puncta per area of CA1 stratum radiatum dendrites. Puncta at least $10 \mu \mathrm{m}$ from the pyramidal layer were analyzed. One-way ANOVA revealed a significant main effect of treatment $\left(F_{2,10}=25.45, \quad p=0.0001\right)$. Newman-Keuls post hoc test revealed Ro-25-6981 (0.57 \pm 0.02 puncta/ $\mu \mathrm{m}^{2}$ normalized to control, $\left.n=4\right)$ significantly decreases PLA puncta compared to control $\left(1.0 \pm 0.09 \mathrm{puncta} / \mu^{2}\right.$ normalized, $\left.n=4\right)$, but blocking $\mathrm{GABA}_{\mathrm{B}} \mathrm{Rs}$ with $\mathrm{CGP} 35348$ increases the number of puncta $\left(1.47 \pm 0.10\right.$ puncta $/ \mu \mathrm{m}^{2}$ normalized, $\left.n=5\right)$ compared to both other treatments. c One-way ANOVA revealed a significant main effect of treatment $\left(F_{2,24}=6.157, p=0.0069\right)$ in the FST. Newman-Keuls post hoc test revealed Fmrl KO animals treated with Ro-25-6981 + CGP35348 (41.6 $\pm 13.7 \mathrm{~s}, n=9)$ significantly decrease immobility in the FST compared to control $(151.5 \pm 21.9 \mathrm{~s}, n=9)$, whereas treatment with Ro-25-6981 alone does not $(133.5 \pm 31.9 \mathrm{~s}$, $n=9)$. WT data from Fig. 1 depicted on the $y$-axis for reference. d Similarly, one-way ANOVA revealed a significant main effect of treatment $\left(F_{2,24}=9.616, \quad p=0.0009\right)$ in the splash test. Newman-Keuls post hoc test revealed Ro-25-6981 + CGP35348 (7.4 \pm 1.3 times per minute, $n=10)$ significantly increases grooming frequency in the splash test compared to control $(0.88 \pm 0.30$ times per minute, $n=9$ ) but not Ro-25-6981 treatment only (3.5 \pm 1.2 times per minute, $n=8$ ) for Fmrl KO animals. WT data from Fig. 1 depicted on the $y$-axis for reference. e Updated rapid antidepressant signaling mechanism model $[11,25,26]$ to include RIP-Seq results. Under baseline conditions, activated NMDARs increase intracellular calcium, which activates mTORC1 (left panel). With NMDAR antagonists like ketamine and Ro-25-6981, NMDARs are blocked but activate the release or binding of mRNAs from the RNA-binding protein FMRP (middle panel). Among these released transcripts is $\mathrm{GABA}_{\mathrm{B}} \mathrm{R}$ mRNA, which is translated into newly synthesize $\mathrm{GABA}_{\mathrm{B}} \mathrm{Rs}$ [25]. Old $\mathrm{GABA}_{\mathrm{B}} \mathrm{Rs}$ and the GIRK channels they are coupled to undergo endocytosis [26]. Newly synthesized $\mathrm{GABA}_{B}$ Rs are coupled to L-type calcium channels and, upon activation, increase intracellular calcium, activating mTORC1 (right panel) [26]. mTORC1-dependent transcripts are released from or bound to FMRP, including those mediating a transsynaptic signal that recruits presynaptic engagement to help form new synapses. Yellow boxes with stars indicate the new steps added to the model based on the current data presented. Bars represent mean \pm SEM. $* p<0.05, * * p<0.01, * * * p<0.001, * * * * p<0.0001$

control KO animals (Fig. 5d). Importantly, CGP35348 alone does not increase PSD/SYN1 puncta (Fig. S5D, E), nor does it affect performance in the FST [11] or splash test (Fig. S5F) in Fmrl KO mice. Thus, our data indicate that the rapid antidepressant efficacy of Ro-25-6981 requires FMRP expression, and treatment with Ro-25-6981 regulates mTORC1/FMRP-target mRNAs that promote transsynaptic signaling and synaptogenesis. However, in cases where FMRP expression is absent, as in Fmrl KO animals, Ro-256981 is ineffective as a rapid antidepressant. Only when $\mathrm{GABA}_{\mathrm{B}} \mathrm{R}$ activity is blocked in these animals does Ro-256981 increase synaptogenesis and promote antidepressantlike effects.

\section{Discussion}

Previously, we discovered that the molecular mechanism underlying the behavioral efficacy of rapid antidepressants requires $\mathrm{GABA}_{\mathrm{B}} \mathrm{R}$-mediated mTORC1 activity (Fig. 5e) $[11,25,26]$. Here, we demonstrate that rapid antidepressants regulate mTORC1-sensitive FMRP-target mRNAs that are involved in transsynaptic signaling. While both FMRP and mTORC1 are independently implicated in transsynaptic signaling in Drosophila and cultured neurons [47-49], our results are the first to demonstrate their coordinated regulation of the transsynaptic signaling required for effective pharmacological therapy in a mammalian model. To this end, we show, with our newly developed assay that detects synapse formation, that rapid antidepressant treatment in conjunction with $\mathrm{GABA}_{\mathrm{B}} \mathrm{R}$ activity promotes synaptogenesis in vitro and in vivo in WT animals, but not in a preclinical model of FXS (Fmrl KO mouse). These data collectively confirm the necessity of FMRP expression for the efficacy of rapid antidepressants.

Surprisingly, in Fmrl $\mathrm{KO}$ animals, $\mathrm{GABA}_{\mathrm{B}} \mathrm{R}$ activity prevents the new synapse formation and behavioral effects observed with rapid antidepressant treatment. However, blocking $\mathrm{GABA}_{\mathrm{B}} \mathrm{Rs}$ rescues these detrimental effects in Frml KO mice and promotes the rapid antidepressant effects similar to what we see in WT animals. Paradoxically, clinical trials suggest that treatment with the $\mathrm{GABA}_{\mathrm{B}} \mathrm{R}$ agonist baclofen improves irritability and social responsiveness in people with FXS and ASD; however, these results are mixed [50-52]. Moreover, baclofen can cause adverse side effects, including hyperactivity and anxiety in FXS patients [53-55]. Our results raise the question of why $\mathrm{GABA}_{\mathrm{B}} \mathrm{R}$ signaling is required for synaptogenesis and antidepressant efficacy in WT mice yet prohibitive in Fmrl KO mice. One clue comes from our previous data demonstrating that traditional inhibitory postsynaptic $\mathrm{GABA}_{\mathrm{B}} \mathrm{R}$-GIRK signaling is absent in $\mathrm{Fmrl}$ $\mathrm{KO}$ dendrites and may instead be constitutively excitatory [11]. By blocking $\mathrm{GABA}_{\mathrm{B}} \mathrm{R}$ activity, we may be preventing excessive excitation [56], and the synapse reduction seen in Ro-25-6981-only treated Fmrl KO mice (Fig. 5a, b).

Precision-based medicine holds promise for treatmentresistant MDD patients; however, understanding the underlying cause of treatment resistance is necessary for tailored pharmacotherapy. Herein, our data indicate that treating MDD in people with FXS or an FMR1 premutation may require combination therapy, as traditional [22] and rapid antidepressants alone are not effective in animal models of FXS. FXS is not the only neurological disorder with overactive mTORC1. Tuberous sclerosis complex and Alzheimer's disease also exhibit comorbid MDD and are reported to have overactive mTORC1 signaling [57-59]. Moreover, a recent clinical report indicates that oral 
rapamycin treatment before ketamine prolongs the antidepressant effects of ketamine in a treatment-resistant population [60]. Together, these data support the idea that rapid antidepressants, combined with other drugs that modify mTORC1 activity, such as CGP35348 or rapamycin, may be more effective in populations with certain comorbid conditions. While NMDAR antagonists certainly have revolutionized the treatment of MDD in a general population, caution should be exercised when utilizing them to treat individuals with MDD and mTORC1-related diseases, and combination therapy should be considered.

Dore et al. use a similar PLA assay to detect synapse changes [61].

\section{Data availability}

Sequencing data are available in the NCBI Sequence Read Archive, under submission PRJNA682805.

\section{Code availability}

Code for RNA-Seq analysis is available at https://github. com/snamjoshi/heaney_etal_2021_MP.

Acknowledgements We thank Emma K. Erickson for generating preliminary data associated with this project, Farr Niere for his valuable comments and suggestions, and Olivia Cain for her help running analyses.

Funding This study was supported by National Institutes of Health NINDS R01 NS105005 (KRG) and NS105005-03S1 (KRG), Department of Defense USAMRMC W81XWH-14-1-0061 (KRG), NIH R01 AA026551 (JW), NIH P50 AA025117 (JW); NIAAA R01AA016852, NIAAA T32AA007565 (CFH).

Author contributions KFR-G, CFH, and SVN designed the studies; $\mathrm{CFH}, \mathrm{SVN}, \mathrm{AU}$, and ECB performed the experiments; KFR-G, CFH, and SVN performed analyses; and KFR-G, JLW, CFH, and SVN wrote and edited the manuscript.

\section{Compliance with ethical standards}

Conflict of interest The authors declare that they have no conflict of interest.

Publisher's note Springer Nature remains neutral with regard to jurisdictional claims in published maps and institutional affiliations.

Open Access This article is licensed under a Creative Commons Attribution 4.0 International License, which permits use, sharing, adaptation, distribution and reproduction in any medium or format, as long as you give appropriate credit to the original author(s) and the source, provide a link to the Creative Commons license, and indicate if changes were made. The images or other third party material in this article are included in the article's Creative Commons license, unless indicated otherwise in a credit line to the material. If material is not included in the article's Creative Commons license and your intended use is not permitted by statutory regulation or exceeds the permitted use, you will need to obtain permission directly from the copyright holder. To view a copy of this license, visit http://creativecommons. org/licenses/by/4.0/.

\section{References}

1. Wei Y, Chang L, Hashimoto K. A historical review of antidepressant effects of ketamine and its enantiomers. Pharm Biochem Behav. 2020;190:172870.

2. Li N, Lee B, Liu R-J, Banasr M, Dwyer JM, Iwata M, et al. mTOR-dependent synapse formation underlies the rapid antidepressant effects of NMDA antagonists. Science. 2010;329: 959-64.

3. Duman RS, Li N, Liu R-J, Duric V, Aghajanian GK. Signaling pathways underlying the rapid antidepressant actions of ketamine. Neuropharmacology. 2011;62:35-41.

4. Trullas R, Folio T, Young A, Miller R, Boje K, Skolnick P. 1aminocyclopropanecarboxylates exhibit antidepressant and anxiolytic actions in animal models. Eur J Pharm. 1991;203: 379-85.

5. Murrough JW, Iacoviello B, Neumeister A, Charney DS, Iosifescu DV. Cognitive dysfunction in depression: neurocircuitry and new therapeutic strategies. Neurobiol Learn Mem. 2011; 96:553-63.

6. Duman RS. Ketamine and rapid-acting antidepressants: a new era in the battle against depression and suicide. F1000Res. 2018;7. https://doi.org/10.12688/f1000research.14344.1.

7. Krystal JH, Abdallah CG, Sanacora G, Charney DS, Duman RS. Ketamine: a paradigm shift for depression research and treatment. Neuron. 2019;101:774-8.

8. Workman ER, Niere F, Raab-Graham KF. Engaging homeostatic plasticity to treat depression. Mol Psychiatry. 2017;23: mp2017225-35.

9. Kiebler MA, Bassell GJ. Neuronal RNA granules: movers and makers. Neuron. 2006;51:685-90.

10. Lenzken SC, Achsel T, Carrì MT, Barabino SML. Neuronal RNA-binding proteins in health and disease. Wiley Interdiscip Rev RNA. 2014;5:565-76.

11. Wolfe SA, Workman ER, Heaney CF, Niere F, Namjoshi S, Cacheaux LP, et al. FMRP regulates an ethanol-dependent shift in GABABR function and expression with rapid antidepressant properties. Nat Commun. 2016;7:12867.

12. Dictenberg JB, Swanger SA, Antar LN, Singer RH, Bassell GJ. A direct role for FMRP in activity-dependent dendritic mRNA transport links filopodial-spine morphogenesis to fragile $\mathrm{X}$ syndrome. Dev Cell. 2008;14:926-39.

13. Darnell JC, Klann E. The translation of translational control by FMRP: therapeutic targets for FXS. Nat Neurosci. 2013;16: 1530-6.

14. Abbeduto L, McDuffie A, Thurman AJ. The fragile $\mathrm{X}$ syndrome-autism comorbidity: what do we really know? Front Genet. 2014;5. https://doi.org/10.3389/fgene.2014.00355.

15. Hagerman R, Hoem G, Hagerman P. Fragile $X$ and autism: intertwined at the molecular level leading to targeted treatments. Mol Autism. 2010;1:12

16. Lugenbeel KA, Peier AM, Carson NL, Chudley AE, Nelson DL. Intragenic loss of function mutations demonstrate the primary role of FMR1 in fragile X syndrome. Nat Genet. 1995;10:483-5.

17. Roberts JE, Bailey DB, Mankowski J, Ford A, Sideris J, Weisenfeld LA, et al. Mood and anxiety disorders in females with the FMR1 premutation. Am J Med Genet B Neuropsychiatr Genet. 2009;150B:130-9.

18. Johnston C, Eliez S, Dyer-Friedman J, Hess1 D, Glaser B, Blasey $\mathrm{C}$, et al. Neurobehavioral phenotype in carriers of the fragile $\mathrm{X}$ premutation. Am J Med Genet. 2001;103:314-9. 
19. Bourgeois JA, Seritan AL, Casillas EM, Hessl D, Schneider A, Yang Y, et al. Lifetime prevalence of mood and anxiety disorders in fragile $\mathrm{X}$ premutation carriers. J Clin Psychiatry. 2011;72: 175-82.

20. Kirsch AC, Huebner ARS, Mehta SQ, Howie FR, Weaver AL, Myers SM, et al. Association of comorbid mood and anxiety disorders with autism spectrum disorder. JAMA Pediatr. 2019. https://doi.org/10.1001/jamapediatrics.2019.4368.

21. Weber JD, Smith E, Berry-Kravis E, Cadavid D, Hessl D, Erickson C. Voice of people with fragile X syndrome and their families: reports from a survey on treatment priorities. Brain Sci. 2019;9. https://doi.org/10.3390/brainsci9020018.

22. Uutela M, Lindholm J, Rantamäki T, Umemori J, Hunter K, Võikar V, et al. Distinctive behavioral and cellular responses to fluoxetine in the mouse model for Fragile X syndrome. Front Cell Neurosci. 2014;8:150.

23. Keene JD, Komisarow JM, Friedersdorf MB. RIP-Chip: the isolation and identification of mRNAs, microRNAs and protein components of ribonucleoprotein complexes from cell extracts. Nat Protoc. 2006;1:302-7.

24. Jain R, Devine T, George AD, Chittur SV, Baroni TE, Penalva LO, et al. RIP-chip analysis: RNA-binding protein immunoprecipitation-microarray (Chip) profiling. Methods Mol Biol. 2011;703:247-63.

25. Workman ER, Niere F, Raab-Graham KF. mTORC1-dependent protein synthesis underlying rapid antidepressant effect requires GABABR signaling. Neuropharmacology. 2013;73:192-203.

26. Workman ER, Haddick PCG, Bush K, Dilly GA, Niere F, Zemelman BV, et al. Rapid antidepressants stimulate the decoupling of GABA(B) receptors from GIRK/Kir3 channels through increased protein stability of 14-3-3 $\eta$. Mol Psychiatry. 2015;20:298-310.

27. Niere F, Namjoshi S, Song E, Dilly GA, Schoenhard G, Zemelman BV, et al. Analysis of proteins that rapidly change upon mechanistic/mammalian target of rapamycin complex 1 (mTORC1) repression identifies parkinson protein 7 (PARK7) as a novel protein aberrantly expressed in tuberous sclerosis complex (TSC). Mol Cell Proteom. 2016;15: 426-44.

28. Santarelli L, Saxe M, Gross C, Surget A, Battaglia F, Dulawa S, et al. Requirement of hippocampal neurogenesis for the behavioral effects of antidepressants. Science. 2003;301:805-9.

29. Brachman RA, McGowan JC, Perusini JN, Lim SC, Pham TH, Faye $\mathrm{C}$, et al. Ketamine as a prophylactic against stress-induced depressive-like behavior. Biol Psychiatry. 2016;79:776-86.

30. Surget A, Saxe M, Leman S, Ibarguen-Vargas Y, Chalon S, Griebel $G$, et al. Drug-dependent requirement of hippocampal neurogenesis in a model of depression and of antidepressant reversal. Biol Psychiatry. 2008;64:293-301.

31. Li N, Liu R-J, Dwyer JM, Banasr M, Lee B, Son H, et al. Glutamate N-methyl-D-aspartate receptor antagonists rapidly reverse behavioral and synaptic deficits caused by chronic stress exposure. Biol Psychiatry. 2011;69:754-61.

32. Smith LN, Jedynak JP, Fontenot MR, Hale CF, Dietz KC, Taniguchi $\mathrm{M}$, et al. Fragile $\mathrm{X}$ mental retardation protein regulates synaptic and behavioral plasticity to repeated cocaine administration. Neuron. 2014;82:645-58.

33. Masrour FF, Peeri M, Azarbayjani MA, Hosseini M-J. Voluntary exercise during adolescence mitigated negative the effects of maternal separation stress on the depressive-like behaviors of adult male rats: role of NMDA receptors. Neurochem Res. 2018;43:1067-74.

34. Darnell JC, Van Driesche SJ, Zhang C, Hung KYS, Mele A, Fraser CE, et al. FMRP stalls ribosomal translocation on mRNAs linked to synaptic function and autism. Cell. 2011;146:247-61.
35. Law CW, Chen Y, Shi W, Smyth GK. voom: precision weights unlock linear model analysis tools for RNA-seq read counts. Genome Biol. 2014;15:R29.

36. Antar LN, Bassell GJ. Sunrise at the synapse: the FMRP mRNP shaping the synaptic interface. Neuron. 2003;37:555-8.

37. Huang DW, Sherman BT, Lempicki RA. Bioinformatics enrichment tools: paths toward the comprehensive functional analysis of large gene lists. Nucleic Acids Res. 2009;37:1-13.

38. Huang DW, Sherman BT, Lempicki RA. Systematic and integrative analysis of large gene lists using DAVID bioinformatics resources. Nat Protoc. 2009;4:44-57.

39. Smedley D, Haider S, Durinck S, Pandini L, Provero P, Allen J, et al. The BioMart community portal: an innovative alternative to large, centralized data repositories. Nucleic Acids Res. 2015;43: W589-98.

40. Durinck S, Moreau Y, Kasprzyk A, Davis S, De Moor B, Brazma A, et al. BioMart and bioconductor: a powerful link between biological databases and microarray data analysis. Bioinformatics. 2005;21:3439-40.

41. Durinck S, Spellman PT, Birney E, Huber W. Mapping identifiers for the integration of genomic datasets with the R/Bioconductor package biomaRt. Nat Protoc. 2009;4:1184-91.

42. Südhof TC. Towards an understanding of synapse formation. Neuron. 2018;100:276-93.

43. Micheva KD, Busse B, Weiler NC, O'Rourke N, Smith SJ. Single-synapse analysis of a diverse synapse population: proteomic imaging methods and markers. Neuron. 2010;68:639-53.

44. Benson DL, Watkins FH, Steward O, Banker G. Characterization of GABAergic neurons in hippocampal cell cultures. J Neurocytol. 1994;23:279-95.

45. De Simoni A, Griesinger CB, Edwards FA. Development of rat CA1 neurones in acute versus organotypic slices: role of experience in synaptic morphology and activity. $J$ Physiol. 2003;550:135-47.

46. Chowdhury GMI, Zhang J, Thomas M, Banasr M, Ma X, Pittman $\mathrm{B}$, et al. Transiently increased glutamate cycling in rat PFC is associated with rapid onset of antidepressant-like effects. Mol Psychiatry. 2017;22:120-6.

47. Friedman SH, Dani N, Rushton E, Broadie K. Fragile X mental retardation protein regulates trans-synaptic signaling in Drosophila. Dis Model Mech. 2013;6:1400-13.

48. Henry FE, McCartney AJ, Neely R, Perez AS, Carruthers CJL, Stuenkel EL, et al. Retrograde changes in presynaptic function driven by dendritic mTORC1. J Neurosci. 2012;32:17128-42.

49. Penney J, Tsurudome K, Liao EH, Elazzouzi F, Livingstone M, Gonzalez M, et al. TOR is required for the retrograde regulation of synaptic homeostasis at the Drosophila neuromuscular junction. Neuron. 2012;74:166-78.

50. Berry-Kravis EM, Hessl D, Rathmell B, Zarevics P, Cherubini M, Walton-Bowen K, et al. Effects of STX209 (arbaclofen) on neurobehavioral function in children and adults with fragile $\mathrm{X}$ syndrome: a randomized, controlled, phase 2 trial. Sci Transl Med. 2012;4:152ra127.

51. Berry-Kravis E, Hagerman R, Visootsak J, Budimirovic D, Kaufmann WE, Cherubini M, et al. Arbaclofen in fragile X syndrome: results of phase 3 trials. J Neurodev Disord. 2017;9:3.

52. Erickson CA, Veenstra-Vanderweele JM, Melmed RD, McCracken JT, Ginsberg LD, Sikich L, et al. STX209 (arbaclofen) for autism spectrum disorders: an 8-week open-label study. J Autism Dev Disord. 2014;44:958-64.

53. Henderson C, Wijetunge L, Kinoshita MN, Shumway M, Hammond RS, Postma FR, et al. Reversal of disease-related pathologies in the fragile $\mathrm{X}$ mouse model by selective activation of GABAB receptors with arbaclofen. Sci Transl Med. 2012;4: $152 \mathrm{ra} 128$. 
54. Sinclair D, Featherstone R, Naschek M, Nam J, Du A, Wright S, et al. GABA-B agonist baclofen normalizes auditory-evoked neural oscillations and behavioral deficits in the Fmr1 knockout mouse model of fragile $X$ syndrome. eNeuro. 2017;4: ENEURO.0380-16.2017.

55. Zeidler S, Pop AS, Jaafar IA, de Boer H, Buijsen RAM, de Esch $\mathrm{CEF}$, et al. Paradoxical effect of baclofen on social behavior in the fragile X syndrome mouse model. Brain Behav. 2018;59: e00991.

56. Wahlstrom-Helgren S, Klyachko VA. GABAB receptor-mediated feed-forward circuit dysfunction in the mouse model of fragile $\mathrm{X}$ syndrome. J Physiol. 2015;593:5009-24.

57. Curatolo P, Moavero R, de Vries PJ. Neurological and neuropsychiatric aspects of tuberous sclerosis complex. Lancet Neurol. 2015;14:733-45.
58. Rapp MA, Schnaider-Beeri M, Purohit DP, Perl DP, Haroutunian $\mathrm{V}$, Sano M. Increased neurofibrillary tangles in patients with Alzheimer disease with comorbid depression. Am J Geriatr Psychiatry. 2008;16:168-74.

59. Li X, Alafuzoff I, Soininen H, Winblad B, Pei J-J. Levels of mTOR and its downstream targets 4E-BP1, eEF2, and eEF2 kinase in relationships with tau in Alzheimer's disease brain. FEBS J. 2005;272:4211-20.

60. Abdallah CG, Averill LA, Gueorguieva R, Goktas S, Purohit P, Ranganathan M, et al. Modulation of the antidepressant effects of ketamine by the mTORC1 inhibitor rapamycin. Neuropsychopharmacology. 2020;45:990-7.

61. Dore K, Pao Y, Soria Lopez J, Aronson S, Zhan H, Ghosh S, et al. SYNPLA, a method to identify synapses displaying plasticity after learning. Proc Natl Acad Sci USA. 2020;117:3214-9. 